\title{
Strategi Pemerintahan Xi Jinping terhadap Taiwan dalam M engamankan Kedaulatan Tiongkok
}

\author{
Inneke Firsana Dewi, Karina Utami Dewi \\ Program Studi IImu Hubungan Internasional \\ Universitas Islam Indonesia \\ J. Kaliurang km. 14.5, Sleman, Yogyakarta 55584 \\ innekedewi95@gmail.com \\ Diserahkan: 4 J anuari 2019; diterima: 8 Maret 2019
}

\begin{abstract}
The dynamics of China and Taiwan relation which began with a civil war between the Communist Party and the Nationalist Party have not ended yet. President Tsai Ing-wen rejected the existence of the One China Policy and continued to strive for Taiwan's independence in various ways. On the contrary, President Xi Jinping firmly declined Taiwan independence and insisted on defending Taiwan position as part of Chinese sovereignty. This paper aims to explain the attempt of Chinese government under President Xi Jinping in responding to Taiwan move using the concept of security sector by Buzan, Waever, and de Wilde encompasses the security strategy of the military, political, and economic sectors. Through the analysis form this concept, Chinese government's attempt in military and political sector succeeded to overcome the threat from Taiwan position while in the economic sector, the outcome is not as expected since Taiwanese government intended not to depend on Chinese economics.
\end{abstract}

Keywords: China-Taiwan relation, sovereignty, one china policy, security sector.

\begin{abstract}
Abstrak
Dinamika hubungan Tiongkok dan Taiwan yang dimulai dengan perang saudara antara Partai Komunis dan Partai Nasionalis belum berakhir. Presiden Tsai Ing-wen menolak keberadaan Kebijakan Satu Tiongkok (One China Policy) dan terus memperjuangkan kemerdekaan Taiwan dengan berbagai cara. Sebaliknya, Presiden Xi Jinping dengan tegas menolak kemerdekaan Taiwan dan bersikeras mempertahankan posisi Taiwan sebagai bagian dari kedaulatan Tiongkok. Tulisan ini menganalisis menggunakan konsep sektor keamanan oleh Buzan, Waever, dan de W ilde yang mencakup strategi keamanan sektor militer, politik, dan ekonomi untuk menjelaskan upaya pemerintah Tiongkok di bawah Presiden Xi Jinping dalam menanggapi gerak Taiwan. Melalui analisis dari konsep ini dapat dijelaskan bahwa upaya pemerintah Tiongkok di sektor militer dan politik berhasil mengatasi ancaman dari posisi Taiwan; sementara di sektor ekonomi, hasilnya tidak seperti yang diharapkan karena pemerintah Taiwan secara kontinu berupaya untuk tidak bergantung pada ekonomi Tiongkok.

Kata kunci: hubungan Tiongkok-Taiwan, kedaulatan, kebijakan satu Tiongkok, sektor keamanan.
\end{abstract}

\section{PENDAHULUAN}

Dinamika hubungan Tiongkok dan Taiwan dapat dikatakan sebagai pola hubungan 'subordinasi' dan sudah berlangsung lama. $\mathrm{H}$ al tersebut dikarenakan konflik yang terjadi antara keduanya telah berlangsung sejak tahun 1945. Setelah mengubah sistem monarki menjadi republik, Partai Komunis Tiongkok mengambil alih dan mendeklarasikan Republik Rakyat Tiongkok padatanggal 10 ktober 1949. Partai Kuomintang di bawah pimpinan C hiang KaiShek yang beraliran nasional is membentuk negara sendiri sebagai upaya melepaskan diri dari negara tersebut setelah kekalahannya dalam perang sipil melawan Partai Komunis yang dipimpin oleh M ao Zedong (Sujadmiko, 2010). Insiden tersebut membuat partai beraliran nasionalis ini melarikan diri menuju Pulau Formosa yang kemudian mendirikan Republic of $C$ hina.

Dalam konflik tersebut, Amerika Serikat membantu Taiwan dalam mengatasi berbagai permasalahan dengan Tiongkok. Amerika Serikat menyuplai peralatan militer 
dengan jumlah besar ke Taiwan untuk mengantisipasi ancaman yang diberikan Tiongkok. Perdagangan senjata antara A merika Serikat dan Taiwan ini terusterjal in, hingga pada saat persoalan status kenegaraan Taiwan mulai dipertanyakan, karenaTaiwan tidak mendapat pengakuan internasional sebagai negara merdeka dan berdaulat. Pada saat upaya reunifikasi tersebut, A merika Serikat menunjukkan perannya sebagai negara pelindung Taiwan (Ramadhani, 2018).

Padatahun 1990 hingga 2008, dinamika politik korosif mendominasi hubungan politik Tiongkok dan Taiwan. Pada saat itu, kedua negara tersebut saling menaruh curiga dan masing-masing mempersiapkan berbagai cara mewujudkan kepentingannya (Bush, 2010). D asar dari konflik Tiongkok dan Taiwan di antaranya adalah; pertama, adanya keengganan Presiden Tsai dalam menerima konsensus 1992. Yang mana telah disebutkan pada konsensus tersebut bahwa hanya ada satu Tiongkok melalui kebijakan 0 ne China Policy (A lbert, 2016). Kedua, adanya perangsipil yang masih belum berakhir secara resmi. $\mathrm{H}$ al ini terjadi karena pemerintah Tiongkok tidak mengakui pemerintahan di Taiwan (The Economist, 2014).

Tiongkok menganggap Taiwan sebagai provinsi yang merupakan bagian dari wilayahnya, sehingga tidak memenuhi syarat dalam hubungan negara ke negara. Isu-isu berkaitan dengan Taiwan mendapat posisi penting bagi Tiongkok ketika mengetahui ada keterlibatan Amerika Serikat. Tiongkok berharap A merika Serikat tetap mematuhi adanya prinsip 0 ne $C$ hina Policy begitupun dengan Tai wan yang harus tunduk pada kebijakan yang dibuat oleh pemerintah Tiongkok (Bush, 2017).

Kebijakan 0 neC hina Policy mendapat reaksi negatif dari Taiwan, karena Taiwan tidak berkeinginan bergabung dengan Tiongkok. Taiwan menganggap negaranya telah berdaulat secara de facto dan sudah dapat dikategorikan sebagai sebuah negara. Walaupun Taiwan memberikan reaksi negatif, Tiongkok tetap menjalankan kebijakan 0 ne C hina Policy dengan membuat aturan ketat bagi negara yang ingin menjalin hubungan diplomatik dengan Tiongkok; yang mana negara-negara tersebut tidak diperbolehkan menjalin hubungan dengan Taiwan. Dengan kata lain, dalam 0 ne China Policy ini negara lain harus menghormati dan mengakui kebijakan tersebut dan hanya memilih satu pemerintahan saja apabila ingin tetap bekerja sama dengan Tiongkok (N abhila, 2017).

Pada tahun 2016, Tsai Ing-wen diangkat menjadi presiden pertama perempuan di Taiwan. Pada saat pemilu terjadi, Tiongkok terusmemantau hasil pemilihan presiden sehingga terdapat penolakan dari Tiongkok atas adanya pemilu yang diselenggarakan. Tiongkok tetap berusaha mengatakan bahwa urusan Taiwan merupakan urusan internal bagi Tiongkok. Sehingga Tiongkok menegaskan kembali adanya konsensus 1992 yang harus dihormati (H idriyah, 2016).

Presiden Tsai Ing-wen terus berupaya mendorong kemerdekaan Taiwan dengan berbagai cara. O leh karena itu Xi Jinping bertekad menggagalkan upaya Taiwan untuk dapat memerdekakan diri dari Tiongkok, dan menegaskan untuk tetap menjunjung tinggi prinsip 0 ne $C$ hina Policy. Tiongkok tetap teguh pada klaimnya mengenai Taiwan meski negara ini sudah lebih dari 70 tahun memiliki pemerintahan sendiri, Tiongkok masih bersikeras bahwa kedua belah pihak berada pada satu bendera, namun Presiden Taiwan Tsai Ing-wen menolak hal tersebut (H orton, 2018).

M enyikapi hal ini, Xi Jinping kemudian meningkatkan pengawasan dan tekanan yang bertujuan membatasi kemampuan Tsai dalam memerintah. Keberadaan A merika Serikat dalam membantu Tai wan ditambah berbagai usaha Taiwan lainnya, dilihat sebagai ancaman bagi kepentingan nasional Tiongkok. Dalam usaha mempertahankan Taiwan sebagai bagian dari Tiongkok sekaligus menghadapi potensi ancaman Taiwan terutama terhadap keamanan Tiongkok, berbagai kebijakan kemudian diambil. Mengingat kebangkitan Tiongkok mencakup multisektoral, maka tidak hanya militer yang menjadi fokus keamanan Xi Jinping dalam menyikapi Taiwan, namun juga pada bidang ekonomi dan politik (Kuntic, 2015).

M elihat dinamika seperti yang telah dijelaskan, tulisan ini mencoba menjawab pertanyaan: bagaimana kebijakan Tiongkok terhadap Taiwan dalam mengamankan kedaulatannya? M etode penelitian dan kerangka pemikiran yang akan digunakan untuk menjawab pertanyaan ini akan dibahas lebih detail pada bagian selanjutnya.

\section{METODE RISET}

Metode yang digunakan adalah kualitatif deskriptif 
dengan mengumpulkan data terkait hal-hal yang melatarbelakangi hubungan dan strategi Tiongkok terhadap Taiwan. M ateri-materi lainnya yang dapat mendukung penulisan diperoleh dari buku, artikel ilmiah, berbagai sumber valid dari internet seperti berita, laporan, dan datadata lain yang dianggap relevan, terutama yang diterbitkan 10 tahun terakhir. A gar fokus penelitian lebih spesifik, maka cakupannya dibatasi sejak kepemimpinan Xi Jinping, yaitu mulai tahun 2013.

\section{KERANGKA PEMIKIRAN}

Tulisan ini menggunakan konsep sektor keamanan yang ditulis oleh Barry Buzan, O le Waever, dan Jaap de W ilde. Dalam buku Security: A N ew Framework for A nalysis, Buzan dkk. menjelaskan bahwa keamanan dikategorikan dalam lima sektor yaitu: sektor keamanan, sektor politik, sektor ekonomi, sektor sosial, dan sektor lingkungan (Buzan, Waever, $\&$ de Wilde, 1998). Tiongkok dan Taiwan mempunyai permasalahan dalam bidang keamanan, sehingga konsep sektor keamanan oleh Buzan dkk. dapat mengidentifikasi ancaman yang muncul. Tiongkok merasa posisi Taiwan sebagai negara yang menginginkan kedaulatan, sebagai negara yang merdeka, dan lepas dari Tiongkok, merupakan sebuah ancaman. $\mathrm{H}$ al ini bahkan sudah terjadi sebelum masa pemerintahan Xi Jinping. Sehingga penting untuk melihat upaya-upaya kebijakan Tiongkok dalam mengamankan kepentingan nasionalnya sebagai negara berdaulat. U ntuk membuat analisis dalam tulisan ini lebih fokus, maka dipilih tiga dari lima sektor keamanan oleh Buzan dkk. yaitu sektor militer, sektor politik, dan sektor ekonomi. Pertama, dalam sektor militer, negara merupakan aspek terpenting, keamanan militer berfokus pada kapabilitas pertahanan suatu negara. Kedua, dalam sektor politik, mencakup dalam kedaulatan, ideologi, dan stabilitas organisasi. Kemudian dalam sektor ekonomi, mencakup keuangan, pasar, dan kemampuan negara untuk mempertahankan kesejahteraan negaranya (Buzan, Waever, $\&$ de Wilde, 1998).

\section{HASIL DAN PEMBAHASAN}

Bagian ini menjelaskan bagaimana posisi Taiwan dan mengapa posisi tersebut dapat menjadi ancaman keamanan bagi kedaulatan Tiongkok. Lebih lanjut bagian ini juga mengelaborasi masing-masing sektor keamanan dan bagaimana Tiongkok menyikapi ancaman jika dilihat dari masing-masing sektor tersebut.

\section{POSISI TAIWAN SEBAGAI ANCAMAN BAGI TIONGKOK}

Buzan dkk. menyatakan bahwa ancaman dapat dipengaruhi oleh faktor politik dan sejarah yang tidak harmonis, yang kemudian berdampak pada keamanan terutama sektor militer (Buzan, Waever, \& de W ilde, 1998). Perselisihan antara Tiongkok dan Tai wan telah berlangsung lama bahkan sebelum Xi Jinping menduduki kursi kepresidenan di Tiongkok. Lebih tepatnya, konflik Tiongkok dan Taiwan diawali dengan perang saudara sehingga membuat hubungan kedua negara tersebut tidak harmonis. Bagi Tiongkok, Taiwan merupakan bagian dari wilayahnya di provinsi bagian Fujian yang melakukan pemberontakan. Namun di lain pihak, Taiwan merasa sebagai sebuah negara yang berdaulat sehingga berhak melakukan kerja sama atau hubungan dengan negaralain.

Gerak Taiwan yang dianggap terlalu bebas dalam melakukan kerja sama menimbulkan berbagai dampak yang dapat mengancam Tiongkok. Ancaman tersebut antaralain: pertama, adanya hubungan erat antaraAmerika Serikat dan Taiwan. Amerika Serikat sering muncul dan memosisikan diri sebagai negara yang melindungi Taiwan atas konflik dengan Tiongkok. A palagi, hubungan Amerika Serikat dengan Tai wan dalam bidang persenjataan menjadi erat karena ada ikatan berupa undang-undang. U ndangundang tersebut berisikan janji Amerika Serikat untuk mengirimkan senjata ke Taiwan. Dengan demikian, Amerika Serikat juga berencana menjual persenjataan kepada Taiwan sebesar 1,4 miliar dolar AS (Kompas, 2017). Perjanjian tersebut membantu Taiwan menuju modernisasi militer. Pasokan senjata yang diberikan A merika Serikat ke Taiwan tergolong senjata canggih. Tidak hanya itu A merika Serikat juga memberikan dukungan kelengkapan militer pada Taiwan (D armawan, 2015).

Bantuan senjata dari Amerika Serikat membuat Tiongkok resah karena penguatan dan modernisasi senjata militer ini membuat Taiwan merasa aman dan lebih percaya diri. Terlebih terdapat undang-undang yang mengikat A merika Serikat untuk membantu mempertahankan Taiwan dan yang merupakan sumber utama pasokan senjata 
untuk Taiwan. Sehingga dapat memunculkan potensi persaingan kekuatan atas kedua negara. A pabila Taiwan memiliki kekuatan lebih besar dibanding Tiongkok maka upaya Tiongkok dalam mempertahankan Taiwan akan semakin sulit (Ramadhani, 2018).

Kedua, usaha Taiwan untuk mendapatkan pengakuan sebagai negara berdaulat semakin memberikan dampak pada eksistensi Tiongkok. Dalam keamanan pada sektor politik ini, Buzan dkk. mengungkapkan bahwa salah satu ancaman pada sektor ini adalah adanya penolakan pengakuan kedaulatan (Buzan, Waever, \& de Wilde, 1998). Dalam hal ini, Taiwan menolak bahwa negaranya merupakan bagian dari Tiongkok, sehingga Taiwan berusaha keras agar mendapatkan pengakuan dari negara lain sebagai sebuah negarayang berdaulat. Taiwan berusaha kerasuntuk dapat berpartisipasi dalam Perserikatan Bangsa-Bangsa (PBB), bukan pada saat pemerintahan Tsai Ing-wen saja namun pada pemerintahan sebelumnya, presiden Taiwan juga melakukan hal yang sama (Ponniah, 2017). Hal ini berarti apabila Taiwan mendapat pengakuan secara internasional sebagai sebuah negara, maka secara langsung dapat mengancam kedaulatan Tiongkok dan kebijakan 0 ne China Policy.

Ketiga, demokrasi di Taiwan. Intimidasi Tiongkok memiliki efek negatif terhadap masyarakat Taiwan, khususnya pada kaum muda. M asyarakat Taiwan sangat mendukung diadopsinya demokrasi karena masyarakat dapat bebas menyuarakan pendapatnya dan bebas dari tekanan pemerintah. Sehingga, sulit bagi masyarakat Taiwan untuk menerima sistem otoriter seperti di Tiongkok, terutama terkait dengan kebijakan yang mengintimidasi dan menekan. Buzan, dkk. juga menekankan bahwa salah satu ancaman lain pada sektor politik adalah perihal ideologi (Buzan, Waever, \& de W ilde, 1998). Seperti yang kita ketahui, Tiongkok memiliki sistem pemerintahan yang berlawanan dengan sistem demokrasi seperti digunakan di Taiwan, di mana demokrasi merupakan sistem politik terbuka dan bebas, berkebalikan dengan sistem politik Tiongkok yang cenderung tertutup dan otoriter ketika itu (Wang, 2017).

Keempat, Tiongkok tidak ingin Taiwan merdeka dan jatuh dalam pengaruh negara lain. Contohnya pengaruh kekuasaan Amerika Serikat. A danya kepentingan dan intervensi Amerika Serikat kerap menganggu upaya Tiongkok untuk mempertahankan Taiwan sebagai bagian dari wilayahnya. Dari sisi sejarah, Taiwan pernah dijadikan basis untuk melancarkan serangan ke wilayah Tenggara Tiongkok. Karena Taiwan dipandang sebagai wilayah strategis, yang mana posisi Taiwan terletak di antara Asia Timur dan Asia Tenggara. Tidak heran apabila Amerika Serikat memiliki kepentingan di Taiwan. Seperti diungkapkan oleh Buzan dkk., pelanggaran ataskedaulatan menjadi salah satu ancaman dalam sektor keamanan politik (Buzan, Waever, \& de Wilde, 1998). Dari perspektif Tiongkok, Taiwan merupakan sebuah provinsi yang termasuk dalam kedaulatan Tiongkok yang berarti kegagalan mempertahankan Taiwan berarti kegagalan Tiongkok dalam menjaga stabilitas negaranya (M ubah, 2014).

\section{Grafik 1. PD B Taiwan (dalam Miliar U SD)}

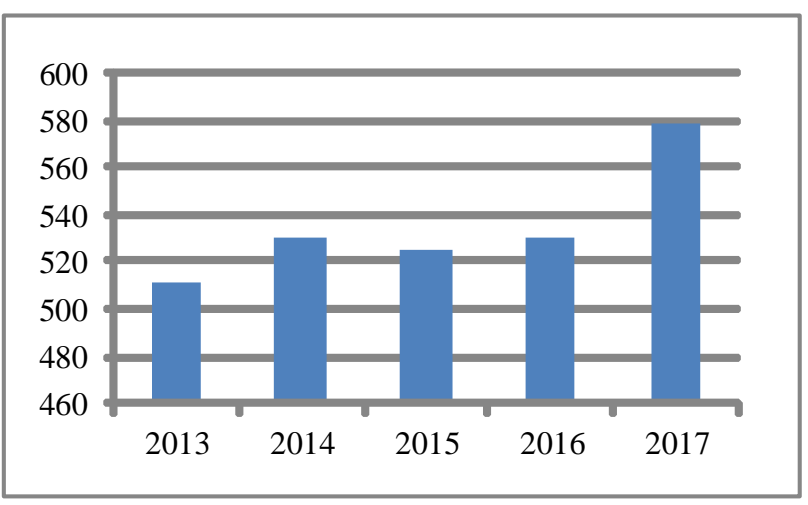

Sumber: Trendings Economics (2018)

Kelima, Taiwan memiliki potensi ekonomi yang cukup besar. Taiwan merupakan salah satu negara yang memiliki pertumbuhan dan ketahanan ekonomi cukup kuat di kawasan A sia. Tidak heran apabila Amerika Serikat dan Tiongkok saling memperkuat pengaruhnya di Taiwan, apalagi terdapat peranan A merika Serikat dalam perekonomian Taiwan. Sehingga, kehilangan Taiwan akan berpotensi memengaruhi stabilitas domestik Tiongkok, seperti disampaikan Buzan dkk. bahwa salah satu ancaman pada keamanan dalam sektor ekonomi akan berdampak pada stabilitas domestik (Buzan, Waever, \& de Wilde, 1998). Hal ini terjadi karena Tiongkok mempunyai hubungan kerja sama ekonomi dengan Taiwan untuk 
meningkatkan kesejahteraan masyarakat Tiongkok. Tiongkok melihat Taiwan sebagai wilayah yang subur dan menyimpan banyak potensi ekonomi untuk dikembangkan. Perekonomian Taiwan dapat tumbuh dengan pesat pada sektor industri dan perdagangan, karena Taiwan memiliki sumber daya manusia yang memadai. Ekonomi Taiwan sebagian besar didorong oleh manufaktur industri, terutama ekspor, industri permesinan, dan petrokimia (Riewpassa, 2014). Terlihat dalam produk domestik bruto (PDB) Taiwan dari tahun ke tahun cenderung menunjukkan kenaikan, seperti terlihat pada Grafik 1.

O leh karena itu, Tiongkok berusaha keras agar Taiwan tetap menjadi bagiannya mengingat perekonomian Tai wan yang semakin kuat. Adanya Taiwan sebagai bagian dari Tiongkok, akan meningkatkan potensi dan perekonomian Tiongkok menjadi lebih kuat dari yang telah dicapai, di mana posisi Tiongkok berada di peringkat kedua setelah A merika Serikat (Saragih, 2018).

\section{SEKTOR MILITER}

Dukungan Amerika Serikat terhadap Taiwan yang cukup besar menjadi ancaman serius bagi Tiongkok. A merika Serikat terus menjual senjata terhadap Taiwan di bawah undang-undang hubungan antara kedua negara tersebut. Tidak hanya persenjataan namun A merika Serikat juga menjual kapal selam ke Taiwan (CNN Indonesia, 2018). Sehingga, Tiongkok mengupayakan beberapa kebijakan antara lain BlokadeM aritim (M aritimeBlockade), O psi Tekanan dan Paksaan Terbatas (L imited Force or C oercive 0 ptions), Kampanye Kekuatan U dara dan Rudal (A ir and $\mathrm{M}$ issile C ampaign), dan Invasi A mfibi (A mphibious Invasion). $\mathrm{H}$ al tersebut merupakan sikap Tiongkok dalam mengatasi ancaman kerja sama militer Taiwan-A merika Serikat yaitu dengan memperkuat militernya untuk mempertahankan kedaulatan (Departement of D efense, 2017). Keempat strategi tersebut merupakan strategi dari People's Liberation A rmy (PLA) atau tentara yang dibawahi oleh pemerintah Tiongkok.

Kebijakan pertama, $\mathrm{M}$ aritime B lockade. PLA menggambarkan kampanye blokade dengan adanya serangan rudal dan penyitaan pulau-pulau lepas pantai Taiwan. Dalam blokade di Taiwan ini, PLA mengancam kapal yang keluar dan masuk dari pelabuhan Taiwan dengan armada kapal selam angkatan laut terbesar di A sia Timur. U paya ini dapat dikatakan mudah bagi Tiongkok karena geoposisi Taiwan yang menguntungkan, apalagi target blokade merupakan sebuah pulau 'kecil' yang hanya terhubung dari udara dan laut (Fan, 2017).

Kedua, Limited Force or C oercive 0 ptions. D alam hal ini, PLA melakukan serangan terhadap infrastruktur atau kepemimpinan di Taiwan yang bertujuan menurunkan kepercayaan masyarakat Taiwan pada pemimpin mereka.

Ketiga, A mphibious Invasion. PLA melakukan kampanye pendaratan pulau bersama, yang bertujuan menerobos pertahanan pantai di Taiwan dan membangun tempat pendaratan. PLA terus meningkatkan kapabilitas dan membangun pendaratan amfibi lebih besar. Dengan adanya pembangunan pendaratan amfibi ini tentu dapat mengangkut lebih banyak barang dan personel PLA.

Keempat, Air and M issile Campaign. PLA tidak segan menggunakan serangan rudal, seperti yang kita ketahui bahwa Tiongkok telah menggelar latihan militer dan telah mengarahkan rudal-rudal balistik ke Taiwan. Tiongkok telah menyiapkan rudal DF-16 yang dapat menyerang Taiwan bahkan dari daya jangkau antara 1.000 sampai 1.500 km. PLA juga telah melakukan modernisasi persenjataan dan kekuatan militernya (Kompas, 2017).

Dalam upaya-upaya yang dilakukan Tiongkok terhadap Taiwan seperti dijelaskan di atas, kemampuan PLA memang telah mengungguli Taiwan. Terlebih Iagi, Tiongkok mempunyai senjata lebih kuat dan mutakhir daripada Taiwan, serta memiliki personel lebih banyak yaitu 0,18\% dari penduduk Tiongkok atau jumlahnya sekitar dua juta lebih (CN N Indonesia, 2018). U paya Tiongkok untuk mempertahankan diri dari ancaman militer Taiwan menggunakan kekuatan militer yang dimiliki menjadi kewajaran untuk membela negaranya (Buzan, Waever, \& de Wilde, 1998).

\section{SEKTOR POLITIK}

Terdapat tiga ancaman dari posisi Taiwan terhadap Tiongkok jika ditilik dari sektor politik, yaitu: usaha Taiwan untuk mendapatkan rekognisi sebagai negara berdaulat; Tiongkok tidak ingin Tai wan merdeka dan jatuh dalam kekuasaan negara lain; serta adanya demokrasi di Taiwan. 
U ntuk mengatasi hal tersebut, Tiongkok mengeluarkan kebijakan politik antara lain dengan Persatuan Garis Depan (A U nited Front), Campur Tangan dalam Politik Taiwan (Interference in Taiwan Politics), dan Isolasi (I solated and A lone). D ari ketiga kebijakan politik tersebut, Tiongkok paling menekankan pada I solated and A lone yaitu Tiongkok mengupayakan untuk menghilangkan Taiwan dari pengakuan resmi forum internasional sementara Presiden Tsai terus berupaya memperjuangkan kebebasan dan demokrasi Taiwan. U ntuk membungkam ambisi Taiwan, Tiongkok menggunakan kekuatannya untuk memutuskan hubungan resmi Taiwan dengan negara lain (Suastha, 2017).

Xi Jinping memutuskan hubungan resmi antara Taiwan dengan negara lain melalui penegasan adanya 0 ne China Policy, yang mana apabila negara lain ingin bekerja sama dengan Tiongkok maka tidak bekerja sama dengan Taiwan karena menurut Tiongkok Taiwan masih berada di bawah wilayah kedaulatannya (Nabhila, 2017). A danya 0 neC hina Policy tersebut, membuat negara yang mengakui secara resmi bahwa Taiwan merupakan sebuah negara, akan terkendala dalam kerja samanya dengan Tiongkok atau bahkan mendapat penolakan. Kurang lebih terdapat 19 negara mengakui Taiwan sebagai sebuah negara, beberapa negara tersebut berada di A merika Tengah (M yers, 2017). Penekanan yang dilakukan oleh Tiongkok secara terusmenerus terhadap negara-negara yang memiliki hubungan diplomatik dengan Taiwan, pada akhirnya menjadi ancaman bagi Taiwan berupa kehilangan dukungan diplomatiknya, antara lain dari EI Salvador, Guatemala, dan H onduras (Perdana, 2018).

Taiwan mengakui bahwa posisinya semakin terpinggirkan dalam dunia internasional akibat upaya Tiongkok yang terus menghalangi Taiwan dalam mendapat pengakuan internasional. Strategi politik ini berhasil melihat status Taiwan saat ini yang belum diakui sebagai sebuah negara berdaulat oleh dunia internasional termasuk PBB. Tiongkok menggunakan strategi campur tangan dalam politik domestik Taiwan sehingga, Tiongkok selalu dapat terlibat dalam permasalahan yang menyangkut Taiwan.

\section{SEKTOR EKONOMI}

Dari sektor ekonomi, Tiongkok memiliki tiga strategi untuk menyiasati kemungkinan terburuk jika akhirnya
Taiwan tidak lagi menjadi bagian kekuasaannya. M engingat Taiwan memiliki andil cukup besar dalam ekonomi Tiongkok, maka strategi ekonomi yang diambil yaitu: pertama, mengurangi jumlah wisatawan yang mengunjungi Taiwan. Pada tahun 2015, jumlah pengunjung dalam penerbangan langsung antara Tiongkok dan Taiwan mencapai 900 orang per-minggu. D an terdapat lebih dari 9,4 juta orang yang melakukan penerbangan antara Tiongkok dan Taiwan padatahun 2014. Namun, pada saat Tiongkok mengurangi jumlah wisatawan yang mengunjungi Taiwan, jumlah pengunjungkeTaiwan dari Tiongkok turun hingga 20\% dari tahun 2016 ke2017 (Albert, 2016).

Kedua, Tiongkok berusaha meyakinkan Taiwan bahwa perekonomian Taiwan tidak akan maju apabila tidak ada kerja sama ekonomi dengan Tiongkok. Tiongkok membuat Tai wan bergantung pada perekonomiannya agar hubungan keduanya semakin erat. Tiongkok cukup yakin dengan langkah ini mengingat walaupun Tiongkok dan Taiwan berkonf lik, namun pada sektor ekonomi, khususnya dalam bisnis dan investasi, Tiongkok dan Tai wan merupakan mitra baik sejak tahun 2002 di mana Tiongkok telah menjadi mitra dagang terbesar bagi Taiwan (H idriyah, 2016).

Ketiga, mempermudah masyarakat Taiwan untuk bekerja di Tiongkok. C hina Taiwan A ffairs mengumumkan bahwa terdapat 31 kebijakan preferensi baru yang dibuat oleh Tiongkok yang bertujuan menarik masyarakat Taiwan untuk berinvestasi dan berkarir serta tinggal di Tiongkok (Schubert, 2018), yaitu dengan memberikan perlakuan sama dengan masyarakat Tiongkok lainnya. D ari 31 kebijakan tersebut, 12 di antaranya berkaitan dengan fasil itas akses pasar dan persaingan perusahaan Taiwan yang berada di Tiongkok. Sementara itu, 19 kebijakan lainnya merupakan peluang baru bagi masyarakat Taiwan untuk memiliki pendidikan tinggi, mendirikan usaha baru, atau dapat bergabung sebagai tenaga kerja di Tiongkok. C ontohnya masyarakat Taiwan dijanjikan mendapat akses industri yang lebih baik, menjadi tenaga profesional dan tidak ada batasan administratif. Ketiga strategi tersebut sesuai dengan apa yang dikatakan Buzan dkk., bahwa dalam keamanan pada sektor ekonomi suatu negara mengejar kebutuhan ekonomi untuk menyejahterakan negara tersebut (Buzan, Waever, \& de Wilde, 1998: 105).

Dari ketiga strategi tersebut tidak semuanya menun- 
jukkan hasil yang signifikan. Pengurangan jumlah wisatawan yang mengunjungi Taiwan dan mempermudah masyarakat Taiwan untuk bekerja di Tiongkok, cukup berhasil dilihat dari data penurunan jumlah wisata seperti ditunjukkan Grafik 2.

\section{Grafik 2. Pariwisata Taiwan (dalam Miliar U SD)}

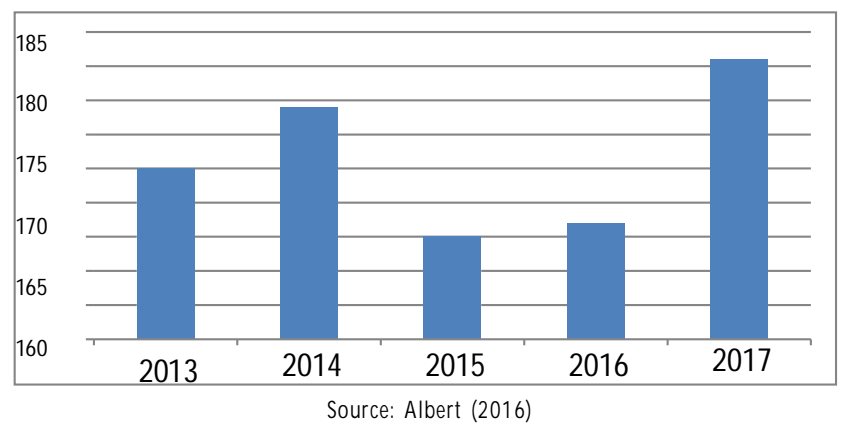

Sementara, upaya Tiongkok meyakinkan Taiwan bahwa perekonomian Taiwan tidak akan maju apabila tidak ada kerja sama ekonomi dengan Tiongkok dapat dikatakan belum berhasil. Hal ini disebabkan Taiwan bersikeras untuk tidak terlalu menggantungkan perekonomiannya pada Tiongkok (Tanasaldy, 2017).

M enurut Tsai Ing-wen, masa depan Taiwan bukan pada Tiongkok, namun pada dunia. $\mathrm{H}$ al tersebut ditunjukkan dengan keberhasilan Taiwan dalam pembangunan ekonomi yang berhasil memiliki daya saing dalam panggung internasional. Terlihat dari sisi pendapatan perkapita, tabungan domestik, dan devisa yang sangat besar, semua hal tersebut merupakan suatu peluang Taiwan untuk dapat meningkatkan perdagangan, memberi bantuan luar negeri, atau menambah investasi luar negeri (Tanasaldy, 2017).

\section{KESIMPULAN}

Strategi Xi Jinping dalam mengamankan kedualatan Tiongkok terhadap Taiwan dapat dilihat dari tiga sektor keamanan yang diajukan oleh Buzan dkk. yaitu sektor militer, sektor politik, dan sektor ekonomi. Dari ketiga klasifikasi tersebut dapat dipetakan strategi mana yang berhasil dan yang dianggap kurang efektif dalam mempertahankan kedaulatan Tiongkok terhadap Taiwan. Dalam strategi sektor militer dan sektor politik untuk mengatasi ancaman dari posisi Taiwan hingga saat ini dapat dikatakan masih mampu membuat Taiwan tetap menjadi bagian dari Tiongkok, atau setidaknya mempertahankan status quo di mana Taiwan tidak mengambil tindakan ekstrem untuk membebaskan diri dari Tiongkok. Sedangkan, pada strategi sektor ekonomi, sebagian upaya oleh Tiongkok berhasil dan yang lainnya mengalami kegagalan karena sampai saat ini Taiwan masih berusaha keras agar perekonomian negaranya tidak bergantung pada Tiongkok.

Perlu menjadi catatan bahwa tulisan ini masih memiliki berbagai keterbatasan, dan tidak menutup kemungkinan bahwa berbagai ancaman yang dirasakan Tiongkok terhadap posisi Taiwan seperti diungkapkan dalam tulisan ini tidak secara mutlak mencakup secara komprehensif, mengingat konflik Tiongkok dan Taiwan yang berkepanjangan dan kompleks. O leh karena itu, penelitian dengan variabel berbeda sangat mungkin menghasilkan kesimpulan yang berbeda, mengingat tulisan ini hanya berfokus pada strategi militer, politik, dan ekonomi di masa pemerintahan Xi Jinping pada tahun 2013-2017.

\section{REFERENSI}

Albert, E. (2016, Desember). China-Taiwan Relations. Council on Foreign Relations. Diakses 28 Mei 2018, dari www.cfr.org/ backgrounder/china-taiwan-relations

Buzan, B., Wæver, O., \& de Wilde, J. (1998). Security: A New Framework for Analysis. Colonado, United States of America: Lymne Rienner Publishers.

Hancock, B., Ockleford, E., \& Windridge, K. (2009). An Introduction to Qualitative Research. NHS National Institute for Health Research, pp. 4-37.

Bush, R. C. (2010, Maret 18). China-Taiwan: Recent Economic, Political, and Military Developments Across the Strait, and Implications for the United States. Brookings. Diakses 4 Oktober 2018, dari https://www.brookings.edu/testimonies/ china-taiwan-recent-economic-political-and-military-developments-across-the-strait-and-implications-for-the-united-states/

Bush, R. C. (2017, Maret 10). A One-China Policy Primer. Brookings. Diakses 1 Juni 2018, dari https://www.brookings.edu/wpcontent/uploads/2017/03/one-china-policy-primer.pdf

CNN Indonesia. (2018, Juni 14). China Kecam Pembukaan 'Kedutaan' AS di Taiwan. AsiaPasifik. Diakses 26 September 2018, dari https://www.cnnindonesia.com/internasional/ 20180613162852-113-305902/china-kecam-pembukaankedutaan-as-di-taiwan

CNN Indonesia. (2018, Juni 06). Ditekan China, Taiwan Gelar Latihan Militer Skala Besar. AsiaPasifik. Diakses 26 September 2018, dari https://www.cnnindonesia.com/internasional/ 20180607164640-113-304351/ditekan-china-taiwan-gelarlatihan-militer-skala-besar

Darmawan, F. E. (2015). Dampak Kerjasama Militer Amerika Serikat-Taiwan Terhadap Hubungan Amerika Serikat-Cina. 
Jurnal Hubungan Internasional, Vol. 2, pp. 1-11.

Wijaya, D. A., Sumardi, \& Sumarjono. (2015). Konflik Perebutan Kekuasaan Antara Kaum Nasionalis dan Komunis di Republik Tiongkok Tahun 1912-1949. Jurnal Universitas Jember, Jilid 1.

Departement of Defense. (2017, M ei 15). Military and Security Developments Involving the People's Republic of China 2017. Annual Report to Congress. Diakses 22 Juli 2018, dari https:// dod.defense.gov/Portals/1/Documents/pubs/ 2017_China_Military_Power_Report.PDF

Fan, B. (2017, April 24). Taiwan's Dilemma: Why a Blockade is Likelier than an Invasion. Taiwan Sentiel. Diakses 11 November 2018, dari https://sentinel.tw/blockade-taiwan-fan/

Hidriyah, S. (2016, Januari 16). Hubungan Politik Taiwan-Tiongkok Pasca Terpilinnya Presiden Baru Taiwan. Kajian Singkat terhadap Isu Aktual dan Strategis, 8, pp. 5-8.

Horton, C. (2018, Februari 28 ). In Taiwan, Young Protesters and Ex-Presidents Chafe Against China. New York Times. Diakses 20 Juli 2018, dari https://www.nytimes.com/2018/02/28/world/ asia/taiwan-chiang-kai-shek.html

Kompas. (2017, Maret 20). China Arahkan Rudal Balistik Jarak Menengah ke Taiwan. Kompas Internasional. Diakses 24 Juli 2018, dari https://internasional.kompas.com/read/2017/03/20/ 18111321/ china. arahkan.rudal.balistik.jarak. menengah.ke.taiwan

Kompas. (2017, Juni 30). AS Jual Senjata 1,4 Miliar Dollar AS ke Taiwan, China Protes Keras. Internasional Kompas. Diakses 16 September 2016, dari https://internasional.kompas.com/read/ 2017/06/30/16473421/

as.jual.senjata.1.4. miliar.dollar. as. ke.taiwan.china.protes. keras

Kuntic, D. (2015). The Ominous Triangle; China-Taiwan-The United States Relationship. CIRR. Diakses 3 November 2018, dari https://hrcak.srce.hr/file/199127

Maulana, F. (2016). Implikasi One China Policy Terhadap Hubungan Luar Negeri Indonesia dan Taiwan dalam Perspektif Hukum Internasional. Diponegoro Law Journal, 5(3).

Mubah, A. S. (2014). Kajian Historis atas Kompleksitas Isu Taiwan dalam Hubungan China dan Amerika Serikat. Departemen Hubungan Internasional, Universitas Airlangga, 2(8).

M yers, C. H. (2017, Juni 13). Panama Establishes Ties With China, Further Isolating Taiwan. New York Times. Diakses 16 September 2018, dari https://www.nytimes.com/2017/06/13/world/ asia/taiwan-panama-china-diplomatic-recognition.html

Nabhila, A. (2017). Indonesia-Taiwan Trade Relations in the Context of One China Policy 2014-2015. Ilmu Hubungan Internasional, pp. 1-81.

Perdana, A. V. (2018, September 22). Taiwan Terancam Kehilangan Tiga Lagi Negara Sekutunya. Internasional Kompas. Diakses 28 September 2018, dari https://internasional.kompas.com/read/ 2018/08/22/22232461/taiwan-terancam-kehilangan-tiga-laginegara-sekutunya

Ponniah, K. (2017, Juni 14). Taiwan: How China Is Poaching The Island's Diplomatic Allies. BBCNews. Diakses 24 September 2018, dari https://www.bbc.com/news/world-asia-40263581

Ramadhani, F. (2018). Dampak Kerjasama Perdagangan Senjata Amerika Serikat Terhadap Peningkatan Ekonomi Taiwan. Jurnal Online Mahasiswa FISIP, April, 5.
Riewpassa. (2014). Pengakuan Amerika Serikat Terhadap China RRC dan China Taiwan. Hubungan Internasional, pp. 1-51.

Saragih, H. P. (2018, Februari 18). 20 Negara dengan PDB Terbesar di Dunia. CNBC Indonesia. Diakses 16 September 2018, dari https://www.cnbcindonesia.com/news/20180218140126-164654/20-negara-dengan-pdb-terbesar-di-dunia

Schubert, G. (2018). China's 31 Preference Policies for Taiwan: An Opportunity, No Threat. TaiwanInsight. Diakses 1 Agustus 2018, dari https://taiwaninsight.org/2018/03/21/chinas-new 31-preference-policies-for-taiwan-an-opportunity-no-threat/

Suastha, R. D. (2017). Peringati Kemerdekaan, Presiden Taiwan Janji Bebas dari China. CNNIndonesia. Diakses 27 September 2018, dari https://www.cnnindonesia.com/internasional/ 20171010124359-113-247375/peringati-kemerdekaanpresiden-taiwan-janji-bebas-dari-china

Sujadmiko, T. (2010). Upaya Cina-Taiwan untuk bergabung dalam International Space Station: Satu Kajian Diplomasi. Peneliti Bidang Pengkajian Kedirgantaraan Internasional, pp. 105-116.

Tanasaldy, T. (2017). Hubungan Luar Negeri Taiwan; Penentu Kebijakan dan Studi Kasus. Jakarta: Yayasan Pustaka Obor Indonesia.

The Economist. (2014, Agustus 26). Why China and Taiwan are Divided. The Economist Explains. Diakses 7 September 2018, dari https://www.economist.com/the-economist-explains/2014/ 08/25/why-china-and-taiwan-are-divided

Tiezzi, S. (2018, Februari 16). A Cross-Strait Chill? You Wouldn't Know It From Taiwan's Economic Data. The Diplomat. Diakses 24 September 2018, dari https://thediplomat.com/2018/02/across-strait-chill-you-wouldnt-know-it-from-taiwans-economicdata/

Trendings Economics. (2018). Trending Economics. Diakses 16 September 2018 https://tradingeconomics.com/taiwan/gdp

Wang, V. W. (2017). Reconciliation without Convergence? ChinaTaiwan Relations in Comparative and Theoretical Perspectives. Paper for Delivery at the ISA International Conference 2017. 